\title{
Dietary diversity score is related to obesity and abdominal adiposity among Iranian female youth
}

\author{
Leila Azadbakht ${ }^{1, *}$ and Ahmad Esmaillzadeh ${ }^{2}$ \\ 'Department of Nutrition, School of Public Health, Isfahan University of Medical Sciences, Isfahan PO Box \\ 81745 , Islamic Republic of Iran: ${ }^{2}$ Nutrition and Food Security Research Center, Isfahan University of Medical \\ Sciences, Isfahan, Islamic Republic of Iran
}

Submitted 25 August 2009: Accepted 10 February 2010: First published online 31 March 2010

\begin{abstract}
Objective: To assess the relationship between diet and disease, consideration of whole-diet indices may be more informative than single-nutrient intake. The present study was conducted to report the relationship among dietary diversity score (DDS), obesity and abdominal adiposity among female university students. Design: Cross-sectional study.

Setting: Isfahan, Iran.

Subjects: A representative sample of 289 healthy female students aged 18-28 years was selected randomly from Isfahan University of Medical Sciences, Iran. Usual dietary intake was assessed using a validated semi-quantitative FFQ. DDS was calculated according to the scoring of the five food groups based on the US Department of Agriculture Food Guide Pyramid. This is a score of diet variety, and shows the diversity of the consumed diet. Participants were categorised on the basis of quartile cut-off points of DDS. Potential confounders such as age, total energy intake and physical activity were considered in all the analyses.

Results: The means (SD) of BMI and waist circumference were $25 \cdot 9$ (SD $5 \cdot 1$ ) kg/m $\mathrm{m}^{2}$ and 85.5 (sD 14) cm, respectively. The probability of obesity decreased with quartiles of DDS (OR among quartiles: $1 \cdot 00,0 \cdot 41,0 \cdot 31$ and $0 \cdot 21, P=0 \cdot 03$; this was the same for abdominal adiposity: $1 \cdot 00,0.55,0.36$ and $0.21, P=0.02$ ). Those in the lowest quartile of the DDS had the highest risk for being overweight.

Conclusions: There were inverse associations among DDS, obesity and abdominal adiposity among the female students of Isfahan University. Further prospective investigations are needed to confirm this finding.
\end{abstract}

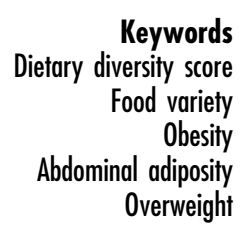

At present, obesity is a major public health concern. According to recent reports, at least 400 million adults are obese and 1.6 billion are overweight worldwide ${ }^{(1)}$. Although the prevalence of obesity has reached $50 \%$ in developed countries, many developing countries face this health problem, especially among women ${ }^{(2)}$. The prevalence of obesity among Iranian women has increased dramatically to $20 \cdot 8 \%$ from $16 \cdot 5 \%$ over 3 years (from 1998 to 2001 , according to a national study) $)^{(3)}$. However, the pattern of body fat distribution is a more important determinant of chronic diseases than general obesity ${ }^{(4,5)}$. In Iran, it has been reported that $67 \%$ of women and $33 \%$ of men above 20 years of age are centrally obese ${ }^{(6,7)}$. A study of secular trends in central fat accumulation in Iran showed a $6 \%$ increase among men and a 9\% increase among women in central adiposity between 1998 and $2002^{(3)}$.

Various dietary and non-dietary factors are related to obesity and abdominal adiposity ${ }^{(8-10)}$. Among dietary factors, the consumption of many nutrients, foods and food groups is reported to be associated with this health problem $^{(11-14)}$. Although paying attention to diet components is important, there are many undiscovered compounds in foods, and possible interactions among nutrients, which suggest using indices of the whole diet and not only a single component ${ }^{(15-17)}$.

To our knowledge, there is little emphasis on overall diet characteristics and obesity in literature in the field of nutrition. Dietary diversity score (DDS) is an indicator for assessing overall diet ${ }^{(18)}$. Eating a more varied diet is associated with higher intake of macro- and micronutrients, as well as higher nutritional adequacy and diet quality ${ }^{(19-22)}$. Furthermore, DDS might be associated with the prevalence of chronic diseases such as metabolic syndrome ${ }^{(23)}$, cancers $^{(24)}$ and $\mathrm{CVD}^{(25,26)}$. Some earlier studies reported protective effects against non-communicable diseases in more varied diets ${ }^{(23-27)}$. Although higher variety score of a diet is associated with increased fibre intake, vitamin $\mathrm{C}$ and calcium, which are inversely correlated to obesity ${ }^{(21)}$, eating a more varied diet is usually associated with higher energy intake $\mathrm{i}^{(19,28-30)}$. Hence, the main question regarding the 
association between DDS, obesity and abdominal adiposity still remains, and it will be interesting to be assessed. Therefore, we conducted a cross-sectional study on female youth to determine the association between DDS, obesity, overweight and abdominal adiposity. We also found an association between the diversity of each food group and overweight, obesity and abdominal adiposity.

\section{Materials and methods}

\section{Subjects}

This cross-sectional study was conducted for a representative sample of female students, aged 18-28 years, from Isfahan University of Medical Sciences in Iran, selected by the multi-stage cluster random sampling method. When choosing the sample for the study, we first considered all the schools at Isfahan University of Medical Sciences, and departments were randomly chosen from each school. From each department some students were chosen randomly from the list of students in the records. In order to select the students in this way, we considered all the students in different stages of socio-economic status. Using this stratified multi-stage cluster random sampling method, both students who were living in dormitories and those who were living with their families were considered in the sample.

A total of 344 female students were invited to participate in the present study, of whom 308 agreed to participate. The response rate was $89 \%$. Nineteen students were excluded because of having consumed medications that affected their weight or because they reported their energy intake outside the range of $3347-17573 \mathrm{~kJ} / \mathrm{d}$ $(800-4200 \mathrm{kcal} / \mathrm{d})$. Therefore, the final analysis has been conducted on 289 students. Written informed consent was obtained from each participant. The study was approved by the research council of the School of Health, Isfahan University of Medical Sciences.

\section{Assessment of dietary intake}

Dietary intake was evaluated by a 168-item semi-quantitative FFQ. All the questionnaires were administered by trained dietitians. The FFQ consisted of a list of foods with a standard serving size. Participants were asked to report their frequency of consumption of each food item during the previous year on a daily (e.g. bread), weekly (e.g. rice and meat) or monthly (e.g. fish) basis. Portion sizes of consumed foods were converted to grams using household measures ${ }^{(31)}$. Each food and beverage was then coded according to the prescribed protocol and analysed for content of energy and the other nutrients using Nutritionist III software (version $7 \cdot 0$; N-Squared Computing, Salem, OR, USA), which was designed for Iranian foods. The reported frequency for each food item was then converted to a daily intake. Validity and reliability of the FFQ have been assessed previously ${ }^{(32)}$.

\section{Assessment of antbropometric measures}

Weight was measured by using digital scales, with the participants wearing minimal clothing and no shoes, and was recorded to the nearest $100 \mathrm{~g}$. Height was measured by using a tape measure while the participants were standing in a normal position with no shoes. BMI was calculated as weight divided by the square of height $\left(\mathrm{kg} / \mathrm{m}^{2}\right)$. To measure waist circumference (WC), the narrowest level was considered and the hip circumference was measured at the maximum level over light clothing. Both of these procedures were carried out by using nonstretchable tape, without any pressure applied to the surface of the body; measurements were recorded to the nearest $0 \cdot 1 \mathrm{~cm}$. Whenever we could not define the narrowest area of the waist, because of a large amount of abdominal fat or extreme thinness, WC was measured immediately below the end of the lowest rib ${ }^{(33)}$. All the measurements were taken by the same person to reduce chances of error.

\section{Assessment of otber variables}

Sociodemographic and physical status information was obtained from the questionnaires. Data on physical activity were collected based on the interviews and expressed as metabolic equivalent hours per week (MET-h/week) ${ }^{(34)}$.

\section{Definition of terms}

Obesity and overweight were defined ${ }^{(35)}$ as BMI $\geq 30 \mathrm{~kg} /$ $\mathrm{m}^{2}$ and $\mathrm{BMI}=25$ to $<30 \mathrm{~kg} / \mathrm{m}^{2}$, respectively. Abdominal adiposity was defined as $\mathrm{WC}>88 \mathrm{~cm}^{(36)}$.

\section{Dietary diversity score}

We used the method described by Kant et al. ${ }^{(37,38)}$ for scoring dietary diversity. This procedure was based on five groups, bread-grains, vegetables, fruits, meats and dairy, based on the food groups introduced by the US Department of Agriculture (USDA) Food Guide Pyramid $^{(39)}$. We considered this food group category because the USDA Food Guide Pyramid provides a balanced healthy diet ${ }^{(39)}$. Furthermore, adherence to this guideline is associated with higher diet quality and mean adequacy of nutrient intake ${ }^{(40)}$. The main groups mentioned were divided into twenty-three subgroups. These subgroups show the dietary diversity across the groups of the Food Guide Pyramid $^{(39)}$. The bread-grain group was divided into seven subgroups (refined bread, biscuits, macaroni, whole grain bread, corn flakes, rice and refined flour). Fruit was divided into two subgroups (fruit and fruit juice, berries and citrus), and vegetables was divided into seven subgroups (vegetables, potato, tomato, other starchy vegetables, legumes, yellow vegetables and green vegetables). There were three subgroups of meat (red meat, poultry, fish and eggs) and also for dairy (milk, yoghurt and cheese). To be counted as a 'consumer' for any of the food group categories, a respondent had to consume at least one-half of the serving in a day as defined by the 
Food Pyramid quantity criteria. Each of the five broad food categories receive a maximum diversity score of 2 out of the 10 possible score points. Total score was the sum of the scores of the five main groups. The maximum and minimum scores of total dietary diversity were between 0 and 10. To calculate the diversity score of each food group, the abovementioned method was used and the subgroups were the same. The maximum and minimum scores of diversity were $0-2$ within each food group. To calculate the diversity score of each food group, we considered a participant a consumer of a food group if he or she consumed at least one-half of the serving of any subgroup in a day as defined by the Food Pyramid quantity criteria. For example, in the bread-grain group, if a person consumed whole grain and macaroni and biscuits, his or her score was calculated as $(3 \div 7) \times 2=0 \cdot 85$. Therefore, the diversity score of the bread-grain group is $0 \cdot 85$.

\section{Statistical methods}

The Statistical Package for Social Science statistical software package version 9.05 (SPSS Inc., Chicago, IL, USA) was used for all statistical analyses. Cut-off points for quartiles of DDS were calculated and participants were categorised based on quartile cut-off points: first, $<3$; second, $3-<5 \cdot 5$; third, 5.5-<8.5; and fourth, $\geq 8 \cdot 5$. Significant differences in general characteristics across quartile categories of DDS were investigated using the ANOVA test. If there was a significant main effect, the Bonferroni test was used to detect pairwise differences. The $\chi^{2}$ test was used to detect any significant differences in the distribution of participants across quartile categories of DDS with regard to qualitative variables. All correlation coefficients reported were calculated as Pearson correlation coefficients. To determine the association of DDS with obesity and abdominal adiposity, we used multivariable logistic regression. The model was controlled for age (years), energy intake $(\mathrm{kJ} / \mathrm{d})$ and physical activity. For abdominal adiposity risk assessment, a second model was also provided in which BMI was further adjusted in addition to the mentioned variables. In all multivariate models, the first quartile of DDS was considered as a reference. The Mantel-Haenszel extension $\chi^{2}$ test was performed to assess the overall trend of an increasing quartile of DDS associated with an increasing or decreasing likelihood of being classified as high risk. To evaluate the association between energy intake and DDS, the linear regression model was used, and multivariable logistic regression was used to determine the association of the diversity of each food group, obesity, overweight and abdominal adiposity.

\section{Results}

Mean and standard deviation of DDS were $6 \cdot 78$ and $1 \cdot 12$, respectively (minimum: $4 \cdot 08$ (SD $1 \cdot 25$ ); maximum: $8 \cdot 31$ (SD $1.55)$ ). When we calculated each group diversity score separately, the maximum and minimum scores of diversity were related to the fruit $(1.78(\mathrm{SD} 0 \cdot 68))$ and bread-grain $(0 \cdot 76$ (SD 0.33)) groups, respectively. Mean and standard deviation of age, physical activity status and anthropometric measures, as well as the distribution of participants with regard to obesity and abdominal adiposity across quartile categories of DDS, is shown in Table 1. Participants in the lower category of DDS were younger and had higher values of anthropometric measures than those in the upper category. The prevalence of obesity was lower among those in the upper category of DDS than those in the lower category. Age and energy-adjusted means for dietary variables across quartile categories of dietary diversity score are presented in Table 2. A higher DDS was associated with a healthier diet, with those in the upper category also consuming less fatty food, and refined grain and more fruit, vegetables and whole grain. The higher DDS was positively associated with total intake of dietary fibre $(r=0 \cdot 33)$, calcium $(r=0 \cdot 41)$ and vitamin C $(r=0 \cdot 38)$.

Multivariate-adjusted OR and $95 \%$ CI for having obesity and abdominal adiposity across quartile categories of dietary diversity score are presented in Table 3. The probability of overweight and obesity, as well as abdominal adiposity, decreased with quartiles of DDS.

Table 1 Characteristics of the female youths by quartiles of dietary diversity score

\begin{tabular}{|c|c|c|c|c|c|c|c|c|}
\hline & \multicolumn{8}{|c|}{ Quartile categories of dietary diversity score* } \\
\hline & \multicolumn{2}{|c|}{$1(n 72)$} & \multicolumn{2}{|c|}{$2(n 73)$} & \multicolumn{2}{|c|}{$3(n 71)$} & \multicolumn{2}{|c|}{$4(n 73)$} \\
\hline & Mean or \% & SD & Mean or \% & SD & Mean or $\%$ & SD & Mean or $\%$ & SD \\
\hline Age (years) & $19 \cdot 0$ & $7 \cdot 0$ & $20 \cdot 0$ & $7 \cdot 0$ & 21.0 & $8 \cdot 0$ & $23.0+$ & $8 \cdot 0$ \\
\hline BMI $\left(\mathrm{kg} / \mathrm{m}^{2}\right)$ & $27 \cdot 3$ & $5 \cdot 5$ & $26 \cdot 3$ & $5 \cdot 4$ & $25 \cdot 9$ & $5 \cdot 1$ & $24 \cdot 1+$ & $4 \cdot 7$ \\
\hline WHR & $0 \cdot 9$ & $0 \cdot 1$ & 0.9 & 0.09 & 0.9 & $0 \cdot 1$ & $0 \cdot 85 t$ & $0 \cdot 1$ \\
\hline Waist girth $(\mathrm{cm})$ & $87 \cdot 0$ & 15.0 & $86 \cdot 0$ & $14 \cdot 0$ & $85 \cdot 0$ & $14 \cdot 0$ & $84.0+$ & $13 \cdot 0$ \\
\hline Physical activity (MET-h/week) & $11 \cdot 8$ & $8 \cdot 1$ & $13 \cdot 1$ & $9 \cdot 6$ & $12 \cdot 9$ & $10 \cdot 7$ & $13 \cdot 3$ & $9 \cdot 5$ \\
\hline $\mathrm{BMI}=25$ to $<30 \mathrm{~kg} / \mathrm{m}^{2}(\%)$ & $16 \cdot 0$ & $5 \cdot 0$ & $9 \cdot 0$ & $2 \cdot 0$ & $7 \cdot 0$ & $2 \cdot 0$ & $5 \cdot 0+$ & $1 \cdot 0$ \\
\hline $\mathrm{BMI} \geq 30 \mathrm{~kg} / \mathrm{m}^{2}(\%)$ & $12 \cdot 0$ & $4 \cdot 0$ & $6 \cdot 0$ & $3 \cdot 0$ & $4 \cdot 0$ & $2 \cdot 0$ & $3 \cdot 0+$ & $2 \cdot 0$ \\
\hline Abdominal adiposity (\%) & $16 \cdot 0$ & $6 \cdot 0$ & $10 \cdot 0$ & $4 \cdot 0$ & $6 \cdot 0$ & $2 \cdot 0$ & $4 \cdot 0+$ & $1 \cdot 0$ \\
\hline
\end{tabular}

WHR, waist-to-hip ratio; MET-h/week, metabolic equivalent hours per week.

${ }^{*}$ Quartile cut-points of DDS are as follows: first, $<3$; second, 3 to $<5.5$; third, 5.5 to $<8.5$; fourth, $\geq 8.5$.

$+P<0.01$ compared to the first quartile. 
OR of having abdominal adiposity became weaker after adjusting for BMI, but still remained significant.

OR for having obesity and abdominal adiposity across quartiles of vegetable diversity score is shown in Fig. 1. Risk of obesity and abdominal adiposity was significantly lower among those in the highest quartile of the vegetable diversity score $(P<0.04$ and $P<0.03$, respectively). The result was the same in the case of the diversity score of fruit and obesity $(P<0 \cdot 04)$, as well as abdominal adiposity $(P<0 \cdot 04)$. There was no significant association between the bread-grain group and the prevalence of

Table 2 Dietary intakes of female students in Isfahan University of Medical Sciences by DDS quartile categories*

\begin{tabular}{|c|c|c|c|c|}
\hline \multirow[b]{2}{*}{ Dietary intakes } & \multicolumn{4}{|c|}{ Quartile categories of DDS } \\
\hline & $1(n 72)$ & $2(n 73)$ & $3(n 71)$ & $4(n 73)$ \\
\hline \multicolumn{5}{|l|}{ Foods $(g / d) \dagger$} \\
\hline Fruitł & 133 & 158 & 166 & $198 \S$ \\
\hline Vegetables|l & 221 & 251 & 289 & $309 \S$ \\
\hline Meat & 79 & 82 & 78 & 88 \\
\hline Whole grains ${ }^{\star \star}$ & 15 & 31 & 40 & $51 \S$ \\
\hline Refined grainstt & 71 & 63 & 54 & $42 \S$ \\
\hline Dairył & 185 & 198 & 205 & $211 \S$ \\
\hline Fast foods $\S \S$ & 209 & 186 & 159 & $123 \S$ \\
\hline
\end{tabular}

DDs, dietary diversity score.

${ }^{*}$ Quartile cut-points of DDS are as follows: first, $<3$; second, 3 to $<5 \cdot 5$; third, $5 \cdot 5$ to $<8.5$; fourth, $\geq 8.5$.

tReported food intakes were adjusted for age and total energy intake. flncludes apples, oranges, bananas, peaches, grapes, strawberries, pears, watermelon, grapefruit, prunes, pomegranates, kiwi, persimmons, raisins, figs, coconuts, apricots and sweet lemon.

$\S P<0.05$ compared to the first quartile.

IlIncludes onions, cucumbers, lettuces, carrots, cauliflower, Brussels sprouts, kale, cabbage, spinach, mixed vegetables, corn, green beans, green peas, peppers, beets, potatoes, tomatoes, broccoli and celery.

TIncludes beef, liver, chicken hearts and kidneys, meat, poultry, tuna fish and other fishes.

**Includes dark breads (sangak, barbari and taftoon), barley bread, cornflakes, bulgur and germs.

t+Includes white breads (lavash and baguette), noodle, pasta, rice, toasted bread, milled barley, sweet bread, white flour, starch and biscuits.

¥¥Includes milk, yoghurt and cheeses.

$\S \S$ Includes hamburger, sousages, processed meats and pizza. obesity and abdominal adiposity. This was the case for the diversity score of both the meat group and the dairy group.

There was a significant and positive correlation between DDS and total energy intake in the present study $\left(R^{2}=0 \cdot 40 ; P<0 \cdot 05\right)$.

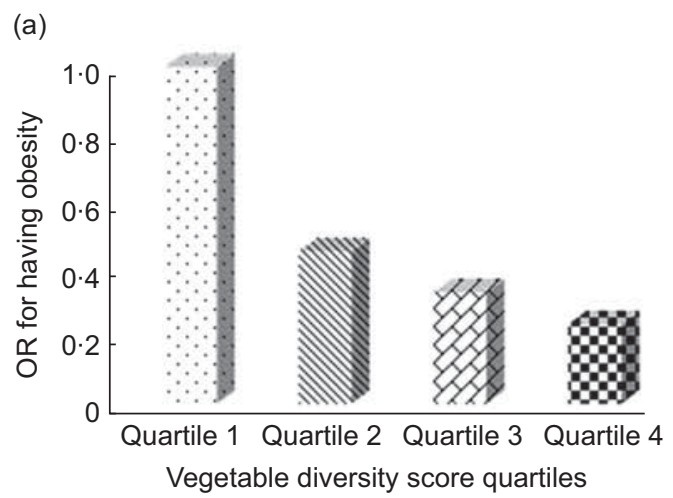

(b)

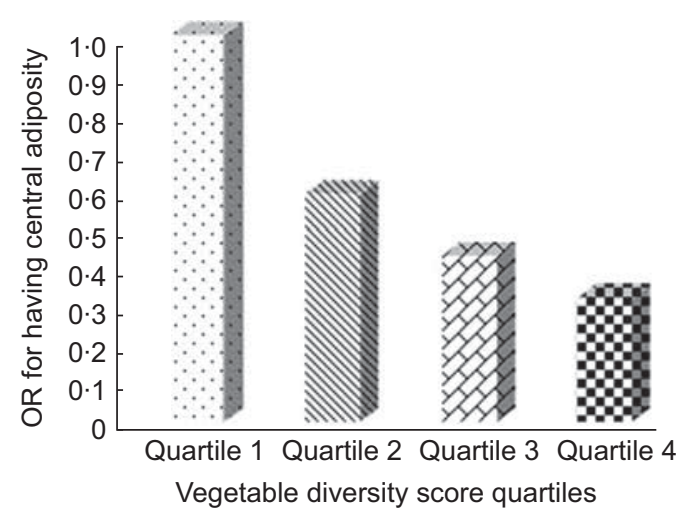

Fig. 1 (a) OR for having obesity $(P$ for trend $=0.04)$ and (b) abdominal adiposity ( $P$ for trend $=0.03$ ) across quartiles of vegetable diversity score

Table 3 Multivariate-adjusted OR and $95 \% \mathrm{Cl}$ for having abdominal adiposity, overweight and obesity across quartile categories of DDS

\begin{tabular}{|c|c|c|c|c|c|c|c|c|}
\hline \multirow[b]{3}{*}{ Risk factors } & \multicolumn{7}{|c|}{ Quartile categories of DDS* } & \multirow[b]{3}{*}{$P$ for trenc } \\
\hline & \multirow{2}{*}{$\begin{array}{c}1 \\
\text { OR }\end{array}$} & \multicolumn{2}{|c|}{2} & \multicolumn{2}{|c|}{3} & \multicolumn{2}{|c|}{4} & \\
\hline & & OR & $95 \% \mathrm{Cl}$ & OR & $95 \% \mathrm{Cl}$ & OR & $95 \% \mathrm{Cl}$ & \\
\hline \multicolumn{9}{|c|}{ Abdominal adiposity } \\
\hline Model 1† & 1.00 & 0.55 & $0.22,1.49$ & 0.36 & $0.11,0.98$ & 0.21 & $0.06,0.98$ & 0.02 \\
\hline Model 2ł & 1.00 & 0.59 & $0.26,1.58$ & 0.39 & $0.19,1.05$ & 0.22 & $0.09,1.09$ & 0.03 \\
\hline Model $3 \S$ & 1.00 & 0.64 & $0.32,1.65$ & 0.45 & $0.21,1.09$ & 0.28 & $0 \cdot 11,1 \cdot 12$ & 0.04 \\
\hline \multicolumn{9}{|l|}{ Overweight } \\
\hline Model 1 & 1.00 & 0.54 & $0.21,1.45$ & 0.38 & $0 \cdot 14,1 \cdot 11$ & 0.22 & $0.07,0.80$ & 0.02 \\
\hline Model 2 & 1.00 & 0.56 & $0.24,1.49$ & $0 \cdot 41$ & $0 \cdot 19,1 \cdot 19$ & 0.23 & $0.09,0.82$ & 0.04 \\
\hline \multicolumn{9}{|l|}{ Obesity } \\
\hline Model 1 & 1.00 & 0.41 & $0.13,1 \cdot 35$ & 0.31 & $0.09,1.22$ & 0.21 & $0.06,0.96$ & 0.03 \\
\hline Model 2 & 1.00 & $0 \cdot 43$ & $0.14,1.39$ & 0.34 & $0 \cdot 11,1 \cdot 29$ & 0.25 & $0.09,0.98$ & 0.04 \\
\hline
\end{tabular}

DDS, dietary diversity score.

${ }^{*}$ Quartile cut-points of DDS are as follows: first, $<3$; second, $3-<5 \cdot 5$; third, $5 \cdot 5-<8 \cdot 5$; fourth, $\geq 8 \cdot 5$.

tAdjusted for age and physical activity.

$\ddagger$ Adjusted for age, physical activity and total energy intake.

§Adjusted for BMI. 


\section{Discussion}

The present study, conducted for a representative sample of Iranian female university students, showed an inverse association of DDS with obesity and abdominal adiposity. We used this population because there is little nutritional information specific for this group in Iran. Furthermore, data on dietary characteristics and abdominal adiposity are rare. Moreover, we are not aware of any nutritional study on female students of Isfahan University of Iran. As DDS reflects a holistic view of the diet, it is a useful indicator for assessing the correlations between diet and diseases.

The results of the present study showed a direct association between energy intake and DDS. Some earlier studies indicated a direct association between DDS and energy intake ${ }^{(28,30)}$. They reported that by increasing DDS, energy intake was also increased. Torheim et $a l^{(41)}$ indicated a positive correlation between energy intake and DDS, as well as variety of different food groups in Mali. The results for Tehranian men were the same ${ }^{(19)}$. Indeed, among Tehranian men energy intake explained $48 \%$ of the variance in the mean probability of nutrient adequacy in the regression model ${ }^{(19)}$. Foot et al. $^{(42)}$ also revealed the role of energy in the association between variety and the mean probability of adequacy in a linear regression model. According to their results, energy was an important component of the regression model. This might prove to be a limitation for a variety of indices in health promotion programmes. The new recommendations advocate consumption of a varied diet while staying within energy needs ${ }^{(43)}$.

In the present study, increase in energy intake was related to increasing energy intakes of fruit, vegetable and whole grains. Therefore, the increasing energy intake, following the increase in DDS, was due to increasing consumption of healthy food groups. Increasing DDS is not always associated with increasing weight, because this index can be increased by consuming more different types of healthy and low-energy-dense food groups such as vegetables, whole grain and fruit. In fact, there is a large variety of vegetables and fruits available in Iran, but refined grain products and meat- or fat-containing commercial products are limited. Therefore, increasing DDS in the Iranian population is mainly achieved by increasing the vegetable or fruit diversity score. In the present study, women who had higher DDS consumed more fruits, vegetables, dairy and grain, which might be correlated with lower incidence of obesity and abdominal adiposity.

Although DDS was correlated with energy intake, after adjusting the total energy intake it was negatively correlated with overweight, obesity and abdominal adiposity. Therefore, another factor such as energy density might play a role in this regard. In fact, by increasing DDS, vegetable, fruit and whole grain intake was also increased. All these groups had low energy density. Therefore, it is suggested that future studies report the correlation between DDS and energy density.
Although DDS was designed according to the food guide pyramid and this pyramid does not control energy intake, those in the top quartile of DDS had lower risk for obesity and overweight, which might be related to their specific choices for increasing the diversity score of their diet. Therefore, they increased their dietary diversity score with low-energy-dense items.

In the present study, diversity scores of vegetable and fruit groups were separately correlated with obesity and abdominal adiposity. None of the earlier studies focused on the diversity score of each food group. This might be considered as a separate analysis that cleared the more specific association between the diversity of food groups and obesity.

Earlier studies indicated that dairy consumption ${ }^{(32)}$, hydrogenated vegetable oil ${ }^{(43)}$, fruit and vegetable intake $^{(44)}$ and whole grain ingestion ${ }^{(45)}$ are associated with metabolic syndrome, one of the important features of which is abdominal adiposity.

Those in the top quartile of DDS had the lowest level of fast food intake. Fast foods are one of the major sources of trans fat intake, which is mainly correlated with abdominal adiposity ${ }^{(46)}$. Fast food consumption might also be correlated with general obesity, abdominal adiposity and other chronic diseases, mainly because of high content of energy and trans fat ${ }^{(9)}$. An analysis of Iranian fast foods and commercial oils also indicated a high amount of trans fats in these kinds of products ${ }^{(47,48)}$. Among the university student population, those who followed a healthier diet had a higher DDS, which was in contrast to the findings of some other studies ${ }^{(28,30)}$. However, in line with the results of the present study, Kant et $a l .{ }^{(49)}$ indicated that DDS was a negative predictor of BMI. In their study, DDS was also an important index for predicting disease.

The results of the present study are not surprising because earlier studies in Iranian populations also indicated an inverse association between this index and metabolic syndrome $^{(23)}$, as well as cardiovascular risk factors ${ }^{(25,26)}$. It seems that DDS among the Iranian population is a good indicator for health, and increasing DDS is favourably associated with metabolic abnormalities. Other studies in other populations also indicated that diverse diet could protect against cancer ${ }^{(50)}$; hypertension ${ }^{(27)}$ and macrovascular diseases among diabetic patients ${ }^{(26)}$. Earlier studies mostly focused on the relationship between cancer and $\operatorname{DDS}^{(24,50,51)}$, whereas the present study provided a possibility to see the relationship between DDS and obesity. Compared to earlier studies on the association between DDS and obesity, the age group and characteristics of the population of the present study (female, university students) was different from other populations ${ }^{(28,30)}$.

DDS is an index for assessing dietary pattern. Even dietary interventions in a population can affect this score ${ }^{(52)}$. Different dietary patterns might be associated with obesity and abdominal adiposity among different populations ${ }^{(53)}$. 
Therefore, focusing on DDS and excluding other aspects of dietary patterns in relation to obesity is questionable.

In the present study, even after adjusting for BMI, DDS was inversely correlated with abdominal adiposity. Although BMI and WC have a high colinearity, this model remained significant even after adjustment.

One of the important strengths of the present study was its consideration of the potential confounders that were adjusted in the reported models of the logistic regression. Potential effects of age, total energy intake and physical activity were adjusted in our analysis.

There are several limitations to the study. The data we used were cross-sectional, and hence a prospective association remains to be identified. Misclassification of the study participants, due to the use of an FFQ, was a concern in our study. Although we tried to control for known confounders, residual confounding cannot be excluded in our findings. The small sample size of the present study was another limitation. However, despite the small sample size, there are few studies in this regard, especially from Middle Eastern countries. Therefore, conducting this research even in a small sample may evoke new ideas in the field of DDS and chronic diseases. The prevalence of obesity was low among the female students. Therefore, it was more effective to analyse the overweight and obese participants together in one model and not in separate models. However, in the present study using tertiles of DDS instead of quartiles was not a useful method to increase cell numbers. It is suggested that future studies should mostly focus on the more prevalent obese groups to determine the association between DDS and obesity. We used a multi-stage randomised sampling method to choose the sample size of the current study. Hence, in this way we tried to have a representative sample of female students in our study. As some of the students were living in the school dormitory, we cannot extrapolate the results of the present study to all the female students in the same age group, and the results are limited to female university students. Furthermore, as the population of the present study was female university students in medical sciences and their level knowledge was higher than others in the same age group, we cannot generalise these results to all the women in this age group. Therefore, there are some concerns regarding the external validity of the current study. The classification of subgroups was based on the USDA Food Guide Pyramid. There is no emphasis on the whole grain intake in this pyramid. Automatically, the bread-grain subgroup classification did not consider the weight of refined and whole grains in its classification. The bread-grain group was heavily weighted for refined grains if a participant ate at least half a serving of refined items in biscuits, cornflakes, macaroni and rice per day. However, the whole grain biscuits and macaroni and whole flour and whole grain cornflakes will be calculated in the mentioned subgroups as well. This means that not only whole grain bread consumption, but also whole grain biscuits, cornflakes or macaroni can increase the diversity score of the bread-grain group. In this way, we cannot say that only whole grain bread among the whole grain items has a role in increasing DDS.

In addition to conducting epidemiological studies, specifically clinical trials, longitudinal trials ${ }^{(54)}$ might determine the effect of consuming more varied diet on weight change. However, increasing the variety score of fruit, vegetable and whole grains could be further emphasised. It is suggested that future studies clarify the association between this score and some possible mediators in the association between DDS and obesity, such as inflammatory factors. However, earlier studies showed some association between food consumption and inflammation ${ }^{(55,56)}$. In addition to considering the association between food and inflammatory markers, paying attention to the dietary pattern and some scores related to dietary variety and inflammation might be useful in describing the association between diet and obesity or abdominal adiposity.

In conclusion, the present study suggests that dietary diversity score is associated with lower risk of obesity and abdominal adiposity. Further prospective investigations should be carried out to confirm this finding.

\section{Acknowledgements}

This study was supported by a grant from the School of Health, Isfahan University of Medical Sciences. The authors have no conflict of interest. The authors are grateful the participants of the study for their enthusiastic cooperation, and they express their gratitude to the research council of the School of Health, Isfahan University of Medical Sciences for financial support. L.A. and A.E. designed the study, collected and analysed the data, and wrote the manuscript.

\section{References}

1. World Health Organization (2008) Fact sheet: obesity and overweight. http://www.who.int/mediacentre/factsheets/ fs311/en/print.html (accessed June 2008).

2. Low S, Chin MC \& Deurenberg-Yap M (2009) Review on epidemic of obesity. Ann Acad Med Singapore 38, 57-59.

3. Azizi F, Azadbakht L \& Mirmiran P (2005) Trends in overweight, obesity and central fat accumulation among Tehranian adults between 1998-1999 and 2001-2002: Tehran lipid and glucose study. Ann Nutr Metab 49, 3-8.

4. Wei M, Gaskill SP, Haffner SM et al. (1997) Waist circumference as the best predictor of non-insulindependent diabetes mellitus compared to BMI, WHR other anthropometric measurements in Mexican Americans: a 7-year prospective study. Obes Res 5, 16-23.

5. Esmaillzadeh A, Mirmiran P, Azadbakht L et al. (2006) Independent and inverse association of hip circumference with metabolic risk factors in Tehranian adult men. Prev Med 42, 354-357. 
6. Azadbakht L, Mirmiran P \& Azizi F (2004) Obesity prevalence and its determinants. Iran J Endocrinol Metab 20, 426-501.

7. Azadbakht L, Mirmiran P, Shiva N et al. (2005) General obesity and central adiposity in a representative sample of Tehranian adults: prevalence and determinants. Int J Vitam Nutr Res 75, 297-304.

8. Azadbakht L \& Esmaillzadeh A (2007) Dietary and nondietary determinants of central adiposity among Tehrani women. Public Health Nutr 11, 528-534.

9. Azadbakht L \& Esmaillzadeh A (2008) Fast foods and risk of chronic diseases. J Res Med Sci 13, 1-2.

10. Jaffiol C (2008) Milk and dairy products in the prevention and therapy of obesity, type 2 diabetes and metabolic syndrome. Bull Acad Natl Med 192, 749-758.

11. Wang Y \& Beydoun MA (2009) Meat consumption is associated with obesity and central obesity among US adults. Int J Obes (Lond) 33, 621-628.

12. Barba G \& Russo P (2006) Dairy foods, dietary calcium and obesity: a short review of the evidence. Nutr Metab Cardiovasc Dis 16, 445-451.

13. Azadbakht L, Mirmiranr R \& Azizi F (2006) Predictors of cardiovascular risk factors in Tehranian adults: diet and lifestyle. East Mediterr Health J 12, 88-97.

14. Azizi F, Mirmiran P \& Azadbakht L (2004) Predictors of cardiovascular risk factors in Tehranian adolescents: Tehran Lipid and Glucose Study. Int J Vitam Nutr Res $\mathbf{7 4}$, 307-312.

15. Hu FB (2002) Dietary pattern analysis: a new direction in nutritional epidemiology. Curr Opin Lipidol 13, 3-9.

16. Newby PK \& Tucker KL (2004) Empirically derived eating patterns using factor or cluster analysis: a review. Nutr Rev 62, 177-203.

17. Kant AK (2004) Dietary patterns and health outcomes. J Am Diet Assoc 104, 615-635.

18. Hatloy A, Torheim LE \& Oshaug A (1998) Food variety: a good indicator of nutritional adequacy of the diet? A case study from an urban area in Mali, West Africa. Eur J Clin Nutr 52, 891-898.

19. Azadbakht L, Mirmiran P \& Azizi F (2005) Variety scores of food groups contribute to the specific nutrient adequacy in Tehranian men. Eur J Clin Nutr 59, 1233-1240.

20. Mirmiran P, Azadbakht L, Esmaillzadeh A et al. (2004) Dietary diversity score in adolescents - a good indicator of the nutritional adequacy of diets: Tehran lipid and glucose study. Asia Pac J Clin Nutr 13, 56-60.

21. Mirmiran P, Azadbakht L \& Azizi F (2006) Dietary diversity within food groups: an indicator of specific nutrient adequacy in Tehranian women. $J$ Am Coll Nutr 25, 354-361.

22. Steyn N, Nel J, Nantel G et al. (2006) Food variety and dietary diversity scores; are they good indicators of dietary adequacy? Public Health Nutr 9, 644-650.

23. Azadbakht L, Mirmiran P \& Azizi F (2005) Dietary diversity score is favorably associated with the metabolic syndrome in Tehranian adults. Int J Obes (Lond) 29, 1361-1367.

24. McCollough ML, Feskanich D, Stampfer MJ et al. (2002) Diet quality and major chronic disease risk in men and women: moving toward improved dietary guidance. Eur J Clin Nutr 57, 930-939.

25. Azadbakht L, Mirmiran P, Esmaillzadeh A et al. (2006) Dietary diversity score and cardiovascular risk factors in Tehranian adults. Public Health Nutr 9, 728-736.

26. Wahlqvist ML, Lo CS \& Myers KA (1989) Food variety is associated with less macrovascular disease in those with type II diabetes and their healthy controls. J Am Coll Nutr $\mathbf{8}$, $515-523$.

27. Miller WL, Crabtree BF \& Evans DK (1992) Exploratory study of the relationship between hypertension and diet diversity among Saba Islanders. Public Health Rep 107, 426-432.

28. Raynor HA \& Epstein LH (2001) Dietary variety, energy regulation, and obesity. Psychol Bull 127, 325-341.

29. Kennedy E (2004) Dietary diversity, diet quality, and body weight regulation. Nutr Rev 62, S78-S81.

30. Raynor HA, Jeffery RW, Tate DF et al. (2004) Relationship between changes in food group variety, dietary intake, and weight during obesity treatment. Int J Obes Relat Metab Disord 28, 813-820.

31. Ghaffarpour M, Houshiar-Rad A \& Kianfar H (1999) The Manual for Household Measures, Cooking Yields Factors and Edible Portion of Foods. Tehran: Keshaverzi Press (In Farsi).

32. Azadbakht L, Mirmiran P, Esmaillzadeh A et al. (2005) Dairy consumption is inversely associated with the prevalence of the metabolic syndrome in Tehranian adults. Am J Clin Nutr 82, 523-530.

33. Wang J, Thornton JC, Bari S et al. (2003) Comparisons of waist circumferences measured at 4 sites. Am J Clin Nutr 77, 379-384.

34. Ainsworth BE, Haskell WL, Whitt MC et al. (2000) Compendium of physical activities: an update of activity codes and MET intensities. Med Sci Sports Exerc 32, S498-S504.

35. Stunkard AJ \& Wadden TA (editors) (1993) Obesity: Theory and Therapy, 2nd ed, p. 45. New York: Raven Press.

36. National Cholesterol Education Program (NCEP) Expert Panel on Detection, Evaluation, Treatment of High Blood Cholesterol in Adults (Adult Treatment Panel III) (2002) Third report of the National Cholesterol Education Program (NCEP) Expert Panel on detection evaluation, and treatment of high blood cholesterol in adults. Circulation 106, 3143-3421.

37. Kant AK, Schatzkin A \& Ziegler RG (1995) Dietary diversity and subsequent cause of specific mortality in the NHANES I epidemiologic follow up study. J Am Coll Nutr 14, 233-238.

38. Kant AK, Schatzkin A, Ziegler RG et al. (1991) Dietary diversity in the US population, NHANES II, 1976-1980. J Am Diet Assoc 15, 1526-1531.

39. US Department of Agriculture (1996) USDA'S Food Guide Pyramid Booklet. Washington, DC: US Department of Agriculture.

40. Mirmiran P, Azadbakht L \& Azizi F (2005) Dietary qualityadherence to the dietary guidelines in Tehranian adolescents: Tehran lipid and glucose study. Int J Vitam Nutr Res 75, 195-200.

41. Torheim LE, Ouattara F, Diarra MM et al. (2004) Nutrient adequacy and dietary diversity in rural Mali: association and determinants. Eur J Clin Nutr 58, 594-604.

42. Foote JA, Murphy SP, Wilkens LR et al. (2004) Dietary variety increases the probability of nutrient adequacy among adults. J Nutr 134, 1779-1785.

43. Esmaillzadeh A \& Azadbakht L (2008) Consumption of hydrogenated vs. non-hydrogenated vegetable oils and risk of insulin resistance and the metabolic syndrome among Iranian adult women. Diabetes Care 31, 223-226.

44. Esmaillzadeh A, Kimiagar M, Mehrabi Y et al. (2006) Fruit and vegetable intakes, C-reactive protein, and the metabolic syndrome. Am J Clin Nutr 84, 1489-1497.

45. Esmaillzadeh A, Mirmiran P \& Azizi F (2005) Whole-grain consumption and the metabolic syndrome: a favorable association in Tehranian adults. Eur J Clin Nutr 59, 353-362.

46. Dorfman SE, Laurent D, Gounarides JS et al. (2009) Metabolic implications of dietary trans-fatty acids. Obesity (Silver Spring) 17, 1200-1207.

47. Asgary S, Nazari B, Sarrafzadegan N et al. (2009) Fatty acid composition of commercially available Iranian vegetable oils. J Res Med Sci 14, 211-215. 
48. Asgary S, Nazari B, Sarrafzadegan N et al. (2009) Fatty acid contents of Iranian Fast Foods. Asia Pac J Clin Nutr 18, 187-192.

49. Kant AK \& Graubard BI (2005) A comparison of three dietary pattern indexes for predicting biomarkers of diet and disease. J Am Coll Nutr 24, 294-303.

50. Fernandez E, Negri E, La Vecchia C et al. (2000) Diet diversity and colorectal cancer. Prev Med 31, 11-14.

51. La Vecchia C, Munoz SE, Braga C et al. (1996) Diet diversity and the risk of colorectal cancer in northern Italy. Cancer Epidemiol Biomarkers Prev 5, 433-436.

52. Sarrafzadegan N, Azadbakht L, Mohammadifard $\mathrm{N}$ et al. (2009) Do lifestyle interventions affect dietary diversity score (DDS) in general population? Public Health Nutr 12, 1924-1930.
53. Esmaillzadeh A \& Azadbakht L (2008) Major dietary patterns in relation to general obesity and central adiposity among Iranian women. J Nutr 138, 358-363.

54. Azadbakht L, Atabak S \& Esmaillzadeh A (2008) Soy protein intake, cardio-renal indices and C-reactive protein in type 2 diabetes with nephropathy: a longitudinal randomized clinical trial. Diabetes Care 3, 648-654.

55. Azadbakht L \& Esmaillzadeh A (2009) Red meat intake is associated with the metabolic syndrome and plasma C-reactive protein levels. J Nutr 139, 335-339.

56. Esmaillzadeh A \& Azadbakht L (2008) Home use of vegetable oils, markers of systemic inflammation, and endothelial dysfunction among women. Am J Clin Nutr 88, 913-921.

\section{Appendix}

The mean and sD of the diversity score within food groups among female students of the university

\begin{tabular}{llr}
\hline Variable & Mean & SD \\
\hline Diversity scores: & & \\
Grain group & $0 \cdot 76$ & $0 \cdot 33$ \\
Vegetable group & $1 \cdot 52$ & $0 \cdot 27$ \\
Fruit group & $1 \cdot 78$ & $0 \cdot 68$ \\
Meat group & $1 \cdot 29$ & $0 \cdot 31$ \\
Dairy group & 1.43 & $0 \cdot 50$ \\
Dietary diversity score & $6 \cdot 78$ & $1 \cdot 12$ \\
\hline
\end{tabular}

